\title{
Effective engagement of conservation scientists with decision-makers
}

\author{
Book or Report Section
}

Published Version

Creative Commons: Attribution-Noncommercial-No Derivative Works 4.0

Open Access

Rose, D. C., Evans, M. C. and Jarvis, R. M. (2020) Effective engagement of conservation scientists with decision-makers. In: Sutherland, W. J., Brotherton, P. N. M., Davies, Z. G., Ockendon, N., Pettorelli, N. and Vickery, J. A. (eds.) Conservation Research, Policy and Practice. Ecological reviews. Cambridge University Press, Cambridge, UK, pp. 162182. ISBN 9781108714587 doi:

https://doi.org/10.1017/9781108638210.010 Available at https://centaur.reading.ac.uk/86620/

It is advisable to refer to the publisher's version if you intend to cite from the work. See Guidance on citing.

To link to this article DOI: http://dx.doi.org/10.1017/9781108638210.010

Publisher: Cambridge University Press

All outputs in CentAUR are protected by Intellectual Property Rights law, including copyright law. Copyright and IPR is retained by the creators or other copyright holders. Terms and conditions for use of this material are defined in the End User Agreement. 


\section{CentAUR}

Central Archive at the University of Reading

Reading's research outputs online 


\title{
Effective engagement of conservation scientists with decision-makers
}

\author{
DAVID C. ROSE \\ University of Reading \\ MEGAN C. EVANS \\ University of Queensland \\ and
}

REBECCA M. JARVIS

Auckland University of Technology and Sydney Institute of Marine Science

\subsection{Introduction}

This chapter offers advice on how the conservation science community can effectively engage with decision-makers. The rationales for why we, as scientists, need to do this have been widely discussed in the literature. Often, the reasons offered are normative, pragmatic, or instrumental (de Vente et al., 2016); in other words, there is a belief that engaging with decision-makers leads to better-informed, more acceptable decisions. Indeed, better engagement may lead to the greater uptake of evidence for conservation decisions, something which some scholars argue is a priority for effective management (e.g. Sutherland \& Wordley, 2017; Gardner et al., 2018).

Engagement with decision-makers of all types is needed because scientific evidence rarely influences policy and practice in a straightforward way; rather, evidence is considered as one part of a 'messy' decision-making progress alongside other forms of knowledge, interests, beliefs, pragmatics and other factors (Lawton, 2007; Adams \& Sandbrook, 2013; Rose, 2014a; Young et al., 2014; Evans et al., 2017). This is particularly true in the case of complex problems, such as biodiversity conservation, where the science is often uncertain, solutions are not readily apparent and the implementation of conservation interventions affects a range of stakeholders with different values and interests (Jarvis et al., 2015a; Maron et al., 2016; Alford \& Head, 2017; Rose, 2018). Appreciating and understanding this complexity is a necessary step for scientists who wish to learn how they can most effectively engage with and influence conservation decisionmaking (Toomey et al., 2016; Evans et al., 2017; Chapter 2). 
Effective engagement with decision-makers can facilitate the use of scientific evidence in decision-making, while building support for interventions that are to be implemented on the ground (de Vente, 2016; Bodin, 2017; Roux et al., 2017). Indeed, there has recently been renewed calls for a 'new kind of science' (Keeler et al., 2017) that is more democratic and inclusive, and explicitly recognises the need to engage stakeholders in the production and utilisation of scientific knowledge (Enquist et al., 2017; Hallett et al., 2017; Wall et al., 2017).

We define engagement as the process by which decision-makers and other stakeholders (including scientists) influence how and what decisions are made. Engagement is a key component of doing conservation work, since conservation decisions will always affect, or be affected, by people (Kareiva \& Marvier, 2007; Kothari et al., 2013). Poorly conducted engagement, however, has the potential to lead to detrimental outcomes (Young et al., 2013; Bodin, 2017; Reed et al., 2017), for example by failing to include all decision-makers in a representative, valued way, or by reinforcing existing power imbalances and inequality (e.g. Chambers, 1997; Brockington, 2007).

So, what does 'effective' engagement look like? Communication is unsurprisingly a fundamental component. Differences in organisational culture, incentives and language can make it difficult for decision-makers and scientists to understand one another (Caplan, 1979; Head, 2015; Newman et al., 2016) and this can lead to scientific evidence being mismatched with the needs of policymakers and practitioners (Jarvis, 2015). Many other studies in conservation have noted that academic science is not always immediately relevant for practitioners (see Walsh et al., 2015). Difficulties in communication include science being presented in jargonistic, unusable formats (Walsh et al., 2015; Marshall et al., 2017;), the lack of open access publishing (Arlettaz et al., 2010), communicating only in one language (Amano et al., 2016) and poorly communicated policy demands (Neßhöver et al., 2016). Overall, Farwig et al. (2017) found that major differences in workflows, background and objectives create a 'researchimplementation gap' (Cook et al., 2013; Jarvis et al., 2015a), which is difficult to bridge. Rose et al. (2018a) found agreement on the major barriers to the use of evidence in conservation policy among policy-makers, scientists and practitioners, but noted that solutions needed to be implemented.

However, effective engagement is not simply a matter of improving communication (Cash et al., 2002; Evans et al., 2017). Knowledge is inevitably coproduced (Miller \& Wyborn, 2018) by multiple groups of people through an iterative process of knowledge exchange, mutual learning, negotiation and adaptation (Cash et al., 2002; Wyborn, 2015). While scientists cannot change the fact that scientific evidence is (necessarily) just one input into conservation decision-making, through effective engagement it is possible to influence how and what knowledge (and decisions) are co-produced (Miller \& Wyborn, 2018). 
Although it is impossible to construct a framework for good engagement that will work in all contexts (de Vente et al., 2016; Bodin, 2017; Reed et al., 2017) common principles of effective engagement include trust, reciprocity, respect, transparency, clear benefits to participants, co-learning and identifying all necessary decision-makers (see Table 10.1; de Vente et al., 2016; Enquist et al., 2017; Reed et al., 2017; Roux et al., 2017; Sterling et al., 2017). Engagement processes should be sensitive to cultural context and power relations and seek to disrupt existing inequalities, rather than reinforce them (Reed et al., 2017; Sterling et al., 2017).

In this chapter, we seek to illustrate common principles of effective engagement using several case studies. We first describe in more detail who the decision-makers in conservation are and how to ensure they are all identified and effectively engaged in a particular context. Next, we outline four case studies that provide examples of good engagement: the development of environmental offsets policy in Australia; community engagement in carnivore conservation in Costa Rica; participatory marine spatial planning in New Zealand; and the development of a code of conduct for marine conservation globally between researchers and NGOs. We conclude by providing 10 'top tips' for scientists engaging with decision-makers, by drawing on the literature, aforementioned case studies and our own experiences.

\subsection{Who are decision-makers in conservation?}

Conservation decisions are made by various individuals and organisations at different levels of governance (Newell et al., 2012; Evans et al., 2017). Throughout this chapter we use 'decision-makers' as an umbrella term to refer to the multiple groups that are involved in conservation policy and practice. The decision-makers involved in a particular conservation issue will vary, as will the local cultures, priorities, knowledge types, values and workflows. Engagement with decision-makers is more likely to be effective if scientists first work to gain an understanding of who may affect or be affected by conservation decisions in a particular context (Waylen et al., 2010; Enquist et al., 2017; Sterling et al., 2017).

It cannot be assumed that good practice for working with one type of decision-maker is transferable to working with another (de Vente et al., 2016; Reed et al., 2017). For example, it is likely that the most appropriate approaches will differ between a government policy-maker, an NGO practitioner, an academic researcher, a farmer and a local resident. Decision-makers will use varying language, hold particular, and personal, worldviews and be part of different decision-making cultures (Blicharska \& Grandin, 2015).

Before engaging, a representative list of key decision-makers needs to be created. Reed et al. (2009) argue that three stages of stakeholder analysis are required at the start of collaborative forms of engagement: (1) identify all key 
actors; (2) differentiate between them by working to understand individual workflows, values, cultures and interests; and (3) understand relationships between actors, to help build alliances or prevent conflict (see also Colvin et al., 2016). A range of methods can be used to map influential decisionmakers (see Reed et al., 2017 for a typology), including interviews, focus groups, Q-methodology, community workshops and the Delphi technique (Amit \& Jacobson, 2018; Mukherjee et al., 2018; Nyumba et al., 2018; Young et al., 2018). Such techniques can help to identify key decision-makers, elucidate how different individuals use and value their land, understand their views on conservation and manage differences between groups.

There is also heterogeneity within groups of decision-makers. For example, in the context of tropical reforestation, Lazos-Chavero et al. (2016) noted that cattle ranchers vary by their age, herd size and educational background. It proved important to engage with a representative group of cattle ranchers because the workflows and priorities of farmers varied with farm size and this influenced uptake of management practices. Indeed, the literature details many such cases where knowledge exchange with practitioners or the public was ineffective because groups were assumed to be homogeneous (Chilvers \& Kearnes, 2016). Taking account of intra-group hetereogeneity as well as intergroup variance thus adds an extra challenge to collaborative processes.

\subsection{Case studies of good engagement}

Many good examples of effective engagement in conservation exist in the literature from terrestrial (Fraser et al., 2006), freshwater (Nel et al., 2016) and marine systems (Granek \& Brown, 2005). The nature of these successes varies from fostering an increased interest in conservation or natural resource management among local communities (e.g. Granek \& Brown, 2005; Fraser et al., 2006; Roux et al., 2017) to traditional knowledge being valued alongside scientific information and fostering inclusivity and trust (Granek \& Brown, 2005) to the formation of better decisions (Fraser et al., 2006; Nel et al., 2016).

Here, we highlight four case studies where engagement with decisionmakers has helped conservation. They present examples of engagement with different types of decision-maker: first with government policymakers, second with stakeholders at the community level, third with multiple stakeholders at a regional level, and fourth with multiple stakeholders at a global level.

\subsubsection{Case Study 1: Engaging with policy-makers - development} of the Australian Environmental Offsets Policy

In 2012, Australian academic researchers formulated a calculation-based approach that set a new standard for determining environmental offset 
requirements. In collaboration with federal policy-makers in the Australian Department of the Environment, the calculation approach was developed into a tool for making fair and robust decisions about offsets. This became the Offsets Assessment Guide, which underpins the Australian Environmental Offsets Policy (2012) (see www.environment.gov.au/system/files/resources/12630bb4-2c104c8e-815f-2d7862bf87e7/files/offsets-policy_2.pdf) and remains the tool for determining offsets for significant impacts on more than 1800 threatened species and ecological communities in Australia (Gibbons et al., 2015; Miller et al., 2015). This collaborative effort between academics and policy-makers was enabled by longterm, effective relationships, significant government investment in research specifically to improve environmental decision-making, ${ }^{1}$ support of senior executive members of the department and a decade of scientific research led by the research team and many colleagues.

Environmental offsets are routinely used as a tool to compensate for unavoidable impacts on biodiversity as a result of development activities such as mining, urban development and agricultural expansion (Maron et al., 2016). In Australia, offsets have been used as conditions of development approval by state and federal governments since the early 2000s (Maron et al., 2015; Evans, 2016). Regulatory decisions under Australia's federal environmental law was guided by a draft policy from 2007 onwards, but stakeholder dissatisfaction with this framework led to a policy review and development of a new draft environmental offsets policy in 2011 (Miller et al., 2015).

Stakeholder consultation led by the federal Department of the Environment indicated broad stakeholder agreement with the new draft policy principles, but also a clear desire for a scientifically robust framework for estimating offset requirements (Miller et al., 2015). The Department then approached academic researchers to develop an offset calculation framework that would enable impacts on threatened species and ecological communities to be adequately and effectively compensated, give effect to the policy principles and be accessible and easy-to-use for all stakeholders (Miller et al., 2015).

The development of the Offsets Assessment Guide was highly collaborative and iterative. Each major revision of the calculation framework produced by the academic researchers was tested by federal government operations staff to ensure ease of use, applicability to a range of decision contexts and adherence to the policy principles. This process of co-design enabled mutual learning and fostered a shared understanding of the different constraints and incentives that policy-makers and academic researchers work under. There was intense negotiation, compromise and robust debate. The researchers had to operate

${ }^{1}$ Specifically, through partnerships with the Australian Government's Commonwealth Environmental Research Facilities (CERF) program (2004-2008), National Environmental Research Program (NERP, 2011-2015) and National Environmental Science Programme (NESP, 2016-2020). 
within a much shorter timeframe than is normally permitted in academia and learned to appreciate the government decision processes and ministerial requirements. The Department of the Environment recognised the need for the collaboration to result in academic publications for the researchers, and publication of work in the academic literature was considered a priority (Miller et al., 2015).

The research outcomes have now shaped environmental offsetting around the world (IUCN, 2016; Maseyk et al., 2016; Cowie et al., 2018). The researchers continue to work with governments, industry, local communities and international convening bodies to boost public and policy-maker capacity to engage with environmental offsets. The final independent report to the Australian Government on the \$154 M National Environmental Research Program highlighted this work as one of the Program's most important impacts (Spencer et al., 2014):

The Offsets Calculator has provided a useful tool to improve the efficiency and effectiveness of regulating development under the EPBC Act by assessing the suitability of offset proposals and assisting with planning and estimating future offset requirements ... The department credits the standing, expertise and assistance of the NERP Environmental Decisions Hub in building stakeholder understanding, trust and acceptance of the offsets policy and calculator, including by industry, NGOs and the jurisdictions. Stakeholder acceptance is crucial to its successful adoption and implementation of this policy.

\subsubsection{Case Study 2: Engaging local communities - co-existence with large carnivores in Costa Rica}

Amit and Jacobson (2018) present an example of community engagement in a project designed to facilitate co-existence between large carnivores (jaguars and pumas) and people in Costa Rica. Through the use of a group decisionmaking technique based on the Delphi process (see Mukherjee et al., 2015), they engaged 133 members of seven communities, as well as 25 multidisciplinary experts from government, NGOs and academic science. Four decision-making rounds were undertaken.

Round one: community representatives were identified by using a database of ranches with the potential for big cat attacks on livestock. After selecting two ranchers and two community leaders from each of seven 'attack hotspots', further participants were identified in consultation with them. At a workshop held at the University of Costa Rica, these local representatives were used to define the project agenda, to identify the major problems, and to brainstorm potential solutions. Draft solutions to incentivise co-existence were developed.

Rounds two and three: the draft incentives were reviewed through online questionnaires sent to a panel of multi-disciplinary experts (NGOs, 
academics, government). The draft list of incentives was iteratively developed based on the opinions of these experts.

Round four: a workshop was held with the communities in each of the seven 'attack hotspots'. They had an average duration of three hours and were conducted by five facilitators at venues such as schools and community halls. Through anonymous voting, and a satisfaction questionnaire, the study team were able to test for consensus, and the willingness of participants to pilot particular incentives.

Detailed results and other methodological information are presented in the original paper (Amit \& Jacobson, 2018). The authors claim that their structured, bottom-up communication process stimulated social learning in a trusting, transparent, collaborative environment. Although one community declined to take part in future research, citing a lack of information provided in the process, the study team argued that the list of incentives for coexistence was able to integrate issues of governance, equity and social norms. As a result, support for the incentives, and for working in a transdisciplinary way, was strengthened in many of the communities.

\subsubsection{Case Study 3: Engagement of multiple stakeholders} and decision-makers at a regional level - the Sea Change - Tai Timu Tai Pari marine spatial planning process

In 2000 the Hauraki Gulf Marine Park (HGMP) was established to recognise the national significance of the Hauraki Gulf/Tìkapa Moana (also known as Te Moananui-ā-Toi) in New Zealand. While a number of management plans were developed over the years to mitigate key threats in the HGMP, they were never implemented. This lack of implementation was due to a lack of stakeholder involvement, weak governance and ineffective management (Hauraki Gulf Forum, 2011, 2014).

In response, Sea Change - Tai Timu Tai Pari was developed in 2013 as a new marine conservation and spatial planning process for the region. In contrast to previous planning efforts, Sea Change - Tai Timu Tai Pari was created as a collaborative, stakeholder-led, co-governance process to design, develop and action a new plan for the HGMP. A Stakeholder Working Group and a number of issues-based roundtables were established to navigate the codevelopment of the plan in consultation with mana whenua iwi and hapu (indigenous Māori tribes and sub-tribes), technical experts, local communities and stakeholders across a range of issues and priorities. This work was supported and assisted by five key partner agencies, including the Hauraki Gulf Forum, Waikato Regional Council, Auckland Council, the Ministry of Primary Industries and the Department of Conservation. In addition, conservation scientists were invited to collaborate with Sea Change - Tai Timu Tai Pari to 
develop participatory tools and approaches to enhance public and stakeholder engagement, while incorporating local knowledge and diverse values, views and priorities into the planning process (Jarvis et al., 2015b, 2016; Jarvis, 2016). The final plan was released in April 2017 (Sea Change - Tai Timu Tai Pari, 2017).

Effective engagement and collaboration was seen as critical for the Sea Change - Tai Timu Tai Pari process and the development of the plan. This highly collaborative approach required negotiation, perseverance and sacrifice, in addition to the vision and commitment offered by those involved. While some work is already underway, the next step of the plan will be broad implementation across all goals and key principles. Strong and effective co-governance will be key to continuing engagement and effective implementation. There are high hopes that mana whenua iwi and hap $\bar{u}$, communities, agencies and government will continue to work together to protect and conserve the future of the HGMP, support healthy and prosperous communities and safeguard this precious natural resource.

\subsubsection{Case Study 4: Engagement of researchers, practitioners} and NGOs at a global level - developing a code of conduct for marine conservation

As marine conservation gathers pace around the globe to achieve our conservation targets and the Sustainable Development Goals, there is a risk that these efforts fail to engage stakeholders and local people effectively. As a result, some actions taken may undermine the rights, dignity and freedoms of local people by not considering their needs or involving them in conservation processes. In response, a code of conduct (COC) was developed to provide a social baseline for how marine conservation should be undertaken, while raising the profile of effective engagement practices and the need for community and stakeholder involvement (Bennett et al., 2017a).

The COC was developed to promote fair governance and decision-making, support social justice and promote transparency and accountability in our marine conservation actions. This includes principles of human rights, indigenous rights and food security, as well as ensuring that marine conservation is carried out in a fair, inclusive way that supports local people. The COC has the potential to have wide-ranging impacts in the way scientists and practitioners undertake marine conservation to ensure it is socially just and environmentally effective.

The lead authors of the proposed code of conduct undertook an initial scoping review and prepared an initial list of principles for discussion with the broader marine conservation community (Bennett et al., 2017a). Next, they convened a meeting with a diverse group of leading experts in marine conservation at the IUCN 2016 World Conservation Congress in Hawaii to 
Table 10.1 Key factors for effective engagement identified in five selected studies

\begin{tabular}{|c|c|c|}
\hline $\begin{array}{l}\text { Paper title and } \\
\text { reference }\end{array}$ & Context & Key principles for good engagement \\
\hline $\begin{array}{l}\text { How does the context } \\
\text { and design of } \\
\text { participatory } \\
\text { decision-making } \\
\text { processes affect their } \\
\text { outcomes? Evidence } \\
\text { from sustainable land } \\
\text { management in } \\
\text { global drylands (de } \\
\text { Vente et al., 2016) }\end{array}$ & $\begin{array}{l}\text { Sustainable land } \\
\text { management in } \\
\text { global drylands }\end{array}$ & $\begin{array}{l}\text { 1. Select participants carefully } \\
\text { 2. Make participation easy } \\
\text { 3. Build trust } \\
\text { 4. Give participants relevant information } \\
\text { 5. Give participants decision-making power } \\
\text { 6. Utilise professional facilitators } \\
\text { 7. Make a long-term commitment } \\
\text { 8. Flexible language, location and design to } \\
\text { the participants }\end{array}$ \\
\hline $\begin{array}{l}\text { Foundations of } \\
\text { translational ecology } \\
\text { (Enquist et al., 2017) }\end{array}$ & $\begin{array}{l}\text { Considers what a new } \\
\text { 'translational } \\
\text { ecology' looks like- } \\
\text { i.e. ecology that is } \\
\text { trans-disciplinary and } \\
\text { inclusive of } \\
\text { stakeholders beyond } \\
\text { academia }\end{array}$ & $\begin{array}{l}\text { 1. Pursue co-production of knowledge } \\
\text { 2. Ensure meaningful engagement with } \\
\text { diverse stakeholders } \\
\text { 3. Make a long-term commitment } \\
\text { 4. Listen and respect views } \\
\text { 5. Ensure everyone can contribute } \\
\text { 6. Have a clear purpose for the engagement } \\
\text { exercise }\end{array}$ \\
\hline $\begin{array}{l}\text { A theory of } \\
\text { participation: what } \\
\text { makes stakeholder } \\
\text { and public } \\
\text { engagement in } \\
\text { environmental } \\
\text { management work? } \\
\text { (Reed et al., 2017) }\end{array}$ & $\begin{array}{l}\text { Narrative literature } \\
\text { search (multiple } \\
\text { contexts) }\end{array}$ & $\begin{array}{l}\text { 1. Understand local context } \\
\text { 2. Include all stakeholders in a transparent } \\
\text { and representative way } \\
\text { 3. Ensure equal participation for all } \\
\text { 4. Match levels of engagement with aims } \\
\text { and strength of values held (longer } \\
\text { engagement needed to change core } \\
\text { beliefs) }\end{array}$ \\
\hline $\begin{array}{l}\text { Trans-disciplinary } \\
\text { research for systemic } \\
\text { change: who to learn } \\
\text { with, what to learn } \\
\text { about and how to } \\
\text { learn (Roux et al., } \\
\text { 2017) }\end{array}$ & $\begin{array}{l}\text { Contemporary } \\
\text { conservation issues } \\
\text { in South Africa }\end{array}$ & $\begin{array}{l}\text { 1. Make a long-term commitment } \\
\text { 2. Use bridging agents or knowledge bro- } \\
\text { kers to improve communication between } \\
\text { groups } \\
\text { 3. Researchers need to present as co- } \\
\text { learners, not 'dominant masters' } \\
\text { 4. Use mixed paradigm research designs } \\
\text { 5. Be conscious of bias, e.g. self-selection, } \\
\text { perceived superiority of scientific knowl- } \\
\text { edge, attraction of simple solutions to } \\
\text { complex problems }\end{array}$ \\
\hline
\end{tabular}


Table 10.1 (cont.)

\begin{tabular}{lll}
\hline $\begin{array}{l}\text { Paper title and } \\
\text { reference }\end{array}$ & Context & Key principles for good engagement \\
\hline $\begin{array}{l}\text { Assessing the evidence } \\
\text { for stakeholder } \\
\text { engagement in }\end{array}$ & $\begin{array}{l}\text { Literature review } \\
\text { (multiple contexts) }\end{array}$ & $\begin{array}{l}\text { 1. Ensure stakeholders can contribute } \\
\text { meaningfully to process }\end{array}$ \\
$\begin{array}{l}\text { biodiversity } \\
\text { conservation (Sterling }\end{array}$ & $\begin{array}{l}\text { 2. Ensure transparency } \\
\text { et al., 2017) }\end{array}$ & $\begin{array}{l}\text { 3. Build trust } \\
\text { 4. Recognise the values of stakeholders }\end{array}$ \\
& $\begin{array}{l}\text { 5. Understand why stakeholders want to } \\
\text { engage }\end{array}$ \\
$\begin{array}{l}\text { 6. Harness stakeholder champions } \\
\text { 7. Make a long-term, trusting commitment } \\
\text { 8. Incorporate local and traditional } \\
\text { knowledge }\end{array}$ \\
$\begin{array}{l}\text { 9. Appreciate and respect local cultural } \\
\text { context }\end{array}$ \\
$\begin{array}{l}\text { 10. Manage stakeholder relationships } \\
\text { flexibly }\end{array}$
\end{tabular}

debate what is considered acceptable and unacceptable in marine conservation with researchers and practitioners from universities, non-profit organisations and government agencies from around the world. The final list of principles was agreed after several rounds of iterations with the authors and workshop participants, incorporating a thorough review of peer-reviewed literature, conservation policies and procedures and foundational policy documents.

The COC (Bennett et al., 2017a) was the result of this collaborative process and was communicated in a wide variety of formats to different media around the world, presented to policy-makers and discussed at high-level meetings, such as the United Nations Ocean Conference in June 2017. As a result, the COC has already been adopted as guiding principles for the Global Environment Facility Blue Carbon Project (GEF, 2017), with partners and beneficiaries that include the United Nations, 40 NGOs and a number of academic institutions, practitioners and members of the scientific community. The objective is for all Blue Carbon Projects to be developed following the COC by 2020. Engagement and discussion around the application of COC more broadly is ongoing. The goal is to establish the $\mathrm{COC}$ as a clearly articulated and comprehensive set of social standards to guide marine conservation actions at multiple scales and ensure that marine conservation goals are met through effective engagement, fair decision-making, accountability and inclusive participatory processes. 


\subsection{Ten tips for achieving good engagement}

There have been few attempts to derive general principles of effective engagement from examples implemented in practice (Nguyen et al., 2017; Reed et al., 2017), as environmental management is such a context-specific endeavour (de Vente et al., 2016). As such, Reed et al. (2009) suggested that approaches to engagement should be flexible, adaptive and iterative based on local circumstances. With this in mind, we highlight 10 tips based on the case studies, the literature and our own experience (see also Table 10.1 for key factors identified in five other studies).

\section{Know who you need to talk to}

This important theme of inclusivity is commonplace in the literature (see Table 10.1). All relevant decision-makers need to be engaged with, or vital knowledge may be missed or unnecessary conflicts created (e.g. de Vente et al., 2016; Enquist et al., 2017; Lazos-Chaveros et al., 2016; Reed et al., 2017). The composition of key decision-makers will always vary with context and may depend on the specific impact that is sought, but robust stakeholder analyses should be conducted before commencement of work (Reed et al., 2009; de Vente et al., 2016). If time or resources are short, then decision-makers may be classified by the extent to which they are affected by a conservation issue (Reed et al., 2009), as Amit and Jacobson (2018) did by identifying 'predator attack hotspots'.

Once decision-makers are identified and engaged with, scientists should seek to differentiate between different groups and understand relationships between them. Part of this process can be an attempt to understand their workflows, their values and culture and even the constraints under which they work. Once groups have been differentiated, then different styles of engagement and conflict management might be needed to work with each (Blicharska \& Grandin, 2015). Furthermore, an appreciation and understanding of political, social and cultural context is always useful (Sterling et al., 2017).

\section{Engage early, with clearly defined aims}

Decision-maker engagement must have a clear purpose in order for all participants to work together towards a clear goal and outcome (Enquist et al., 2017). Involving decision-makers at an early stage of a project may provide ownership of a project to local communities, building support, legitimacy, and trust, as well as leading to the production of relevant, 'use-inspired', or 'actionable' knowledge (Wall et al., 2017). The need for local community-led engagement was illustrated by the examples of human-carnivore co-existence in Costa Rica (Amit \& Jacobson, 2018), marine conservation in New Zealand (Jarvis, 2015; Jarvis et al., 2015) and the biodiversity offsetting project stimulated by the Australian Department of the Environment (Miller et al., 2015). 


\section{Decision-makers should find it easy to engage}

Participation for all decision-makers must be easy (de Vente et al., 2016). For example, meetings should be held in a convenient place for all and project timescales should consider the busy and varied workflows of all decision-makers involved, so as not to disincentivise engagement. Language should also be geared towards participants, and thus a common language and understanding should be developed wherever possible (Amano et al., 2016; de Vente et al., 2016). While we do not necessarily condone offering financial incentives for attendance, researchers could at least consider what the relative advantage of engagement is for decision-makers (what do different decision-makers gain from being part of the process?) and cover costs at the very least (particularly where poorer communities are being involved).

\section{Embrace and include multiple knowledge(s), perspectives and worldviews}

Engagement with decision-makers must be meaningful, and the perspectives and opinions of all stakeholders must be genuinely valued throughout the process (see all studies in Table 10.1). Participation should not merely be tokenistic. The first step towards this is humility on the part of researchers, which fosters a genuine sense to learn from others, while also accepting and appreciating that science is just one input into policy and practical processes. In their study of co-management in South African freshwater ecosystems, Roux et al. (2017) warn against perceived scientific authority, and an attitude that bemoans some decisions made by policy-makers and other stakeholders as irrational if they are not 'evidence-based'. The second step is to find ways of integrating multiple knowledge types into a project, including lay and indigenous knowledges, and local experiential knowledges, and ultimately fostering respect and understanding across different values and motivations (Sterling et al., 2017). The final step is to be able to reflect on your own values and motivations as a conservationist and be prepared to learn from those held by others (Bodin, 2017).

If these steps are followed, it is more likely that a truly collaborative spirit of cooperation will be achieved, which will help to build common understanding of an issue. This will not always mean that everyone agrees, but it will still be possible for all participants to understand each other's point of view. Such a collaborative spirit has been shown to help a range of conservation projects, including in the case studies highlighted above.

\section{Think hard about power}

As researchers, we must do more than simply speak truth to the most obvious powers-that-be (Chambers, 1997); rather, we should seek to 
understand how communities work as thoroughly as possible, something that may require long-term engagement (e.g. using ethnography). LazosChavero et al. (2016) found that paying attention to gender, generational and power disparities in a given region was essential to the success of tropical reforestation schemes. Furthermore, Kleiber et al. (2015) showed that including women in the management of fisheries is essential for conservation success because a significant proportion of fishers are women (something that had often been ignored in previous studies). Thus, ensuring that all stakeholders have equal decision-making power is important for effective engagement. This also includes the balance of power between the stakeholders and the researchers themselves.

\section{Build mutual trust}

This theme is just about universally accepted in the literature and needs little explanation (see Table 10.1). Without mutual trust, transparency and respect, then engagement exercises with decision-makers are doomed to failure. Although Lacey et al. (2018) warn against too much trust (e.g. because this could lead to facts being accepted on 'blind faith'), it is logical to expect that relationships built on trust will yield better results. This is because participants will feel valued and able to challenge the opinion of others. Good practices for building trust include respecting participant confidentiality, following through on promises and committing to long-term engagement if it has been offered.

\section{Good facilitation is key}

Engagement processes need to have good facilitators (de Vente et al., 2016). As illustrated by guides on how to conduct participatory methods, such as focus groups (Nyumba et al., 2018), the facilitator plays a key role in managing group dynamics, encouraging stakeholder input and building trust. A good facilitator will be aware of potential sensitivities within the group (Gibbons et al., 2008) and be able to skilfully avoid and manage conflict, which is so important for a healthy engagement process (Amit \& Jacobson, 2018; Chapter 14). In controversial cases in particular, which are not unusual when dealing with the complex problem of biodiversity loss, the potential for conflict is more pronounced.

\section{Learn new skills for good engagement}

Good engagement and facilitation is helped if the individual is a good communicator. As individuals, it will become increasingly important to develop a range of different skills (as per Jackson et al., 2017) and be able to communicate differently with different people. In doing so, it is important to recognise that conservation can greatly benefit from better use of qualitative methods that 
improve communication, enhance engagement and give voice to others (Mukherjee et al., 2018). However, it may not be possible for individuals to learn all the different skills key for good engagement themselves. Therefore the development of truly inter- and trans-disciplinary teams could be one approach to bring all the necessary tools and skills together and co-design research that properly integrates the natural and social sciences (Bennett et al., 2017b, 2017c) while engaging with stakeholders from the outset and throughout conservation processes (Reed et al., 2017). Where scientists feel unable to facilitate engagement processes effectively, much of the literature suggests using knowledge brokers (alternatively called boundary spanners or bridging agents; Cvitanovic et al., 2015; de Vente et al., 2016; Roux et al., 2017; Bednarek et al. 2018). These individuals have the skills to bridge the gap between varying backgrounds, cultures, interests and languages.

\section{You don't have to reinvent the wheel - consider making use of existing spaces and opportunities}

In conservation, there are several good schemes that encourage scientists to engage better with decision-makers across research, policy and practice (see Elliott et al., 2018 for a global database of 650 conservation capacity initiatives). Such schemes have been developed to reflect requirements for the foundational skills necessary for good engagement while also providing existing opportunities for conservationists to develop their own capacity for effective communication, interpersonal interaction and boundary-crossing. By making use of such schemes, conservation scientists can develop their engagement skills while also being able to better adapt to the changing needs of conservation.

An additional point worthy of consideration is whether conservation researchers make the most of existing informal spaces of engagement to harness the views of decision-makers. Chilvers et al. (2017) criticise engagement processes for usually being established on the terms of researchers. In other words, groups of stakeholders are assembled to talk about an issue that is framed and defined by researchers or policymakers, such as through public forums (see Chilvers \& Kearnes, 2016). Very rarely do we seek to 'listen in' on existing spaces of public participation (e.g. in the village hall, in the pub, on social media) to see what people are concerned about. Could the same criticism be levelled at conservation engagement exercises? Do we seek to assemble groups of decision-makers to discuss conservation issues that we have already framed, rather than asking, for example, local communities to devise the questions of interest (see tip 4)? We suggest that it is important to consider these questions in order that engagement exercises are led by communities, rather than done to them. 


\section{Don't give up!}

The need for long-term engagement is commonly highlighted in the literature (see Table 10.1). One important aspect to take from our recommendations is that they will not always yield immediate, tangible rewards, but this should not be the sole aim of practising good engagement. Rather, ongoing, long-term engagement can lead to a change in the overall policy framing of problems and solutions (Rose et al., 2017), something which can occur diffusely over long timescales (Owens, 2015). Reed et al. (2017) argue that engagement in controversial issues, where people hold deep core values, will need to be more long term (de Vente, 2016; Roux et al., 2017). It can take some time to build the trust and confidence for stakeholders to contribute, and continued engagement after implementation is usually required for conservation projects (Lazos-Chavero et al., 2016). So it is vital not to give up; as Amit and Jacobson (2018) argue, 'participatory decision-making has an inherent phase of struggle and frustration', which is perfectly normal. Sterling et al. (2017) further describe knowledge coproduction as a 'slow' process because it requires long-term committed engagement from all sides.

However, it is also important to note that flexibility of process is also key (Sterling et al., 2017). When inviting decision-makers to contribute to a project, the outcome might be different to the one that the researcher envisaged. Indeed, because you are incorporating multiple values and perspectives into decision-making, the unexpected may be the norm. Most importantly, expect the unexpected and don't give up!

We acknowledge that it is not easy for conservation scientists to initiate and manage collaborative research projects, particularly those that work with a variety of stakeholder groups outside of academia. There are certainly challenges in achieving the new kind of science that Keeler et al. (2017) envisaged (or in embracing the 'post-normal' reality, see Colloff et al., 2017; Rose, 2018), which would be more inclusive of people beyond academia. This includes practical difficulties (e.g. time, money) of engaging decision-makers (Sutherland et al., 2017), as well as the challenge for conservation scientists of developing the skills needed to engage with people, a task for which many of us are not traditionally trained (Jackson et al., 2017). Furthermore, being actively involved with decision-makers might not be something that appeals to individual conservation scientists. Although the boundaries between science, policy and practice are fluid (Rose, 2014b; Toomey et al., 2016), scientists sometimes worry about moving beyond their comfort zone. Yet, if there is a scientific discipline in which advocacy is easier to do, then it should be mission-driven conservation biology (Soulé, 1985; Rose et al., 2018b). 
Ultimately, achieving effective engagement and conservation impact may mean changing the way conservationists work, including those housed in universities and research institutions. One significant challenge is for academic conservation scientists to find the time, motivation and support to engage decision-makers (Chapin, 2017; Keeler et al., 2017; Littell et al., 2017). Often, academics are not rewarded adequately for producing tangible impacts (Jarvis et al., 2015; Tyler, 2017), and activities focused on delivering these impacts are still widely sidelined in favour of career-enhancing academic publication. However, there is no real reason why impact cannot be better incentivised, and new opportunities developed to explore the different ways we can better navigate science, policy and practice. Why, for example, cannot academic departments have dedicated policy teams to highlight policy demand and to foster collaboration with decision-makers? A new kind of conservation science could certainly be imagined, which would reward outreach and incentivise inter-, multi- and trans-disciplinary collaborative work. Where we are unable to invest the time to engage with decision-makers ourselves, we could make much better use of knowledge brokers or boundary spanners (Bednarek et al., 2018).

\subsection{Acknowledgement}

This research was supported by the Australian Government's National Environmental Science Program through the Threatened Species Recovery Hub (MCE).

\section{References}

Adams, W. M. \& Sandbrook, C. 2013. Conservation, evidence and policy. Oryx, 47, 329-335.

Alford, J. \& Head, B. W. 2017. Wicked and less wicked problems: a typology and a contingency framework. Policy and Society, 36, 397-413.

Amano T., González-Varo J. P. \& Sutherland, W. J. 2016. Languages are still a major barrier to global science. PLoS Biology, 14(12), e2000933.

Amit, R. \& Jacobson, S. K. 2018. Participatory development of incentives to coexist with jaguars and pumas. Conservation Biology, 32, 938-948. https://doi.org/10.1111/cobi .13082

Arlettaz, R., Schaub, M., Fournier, J., et al. 2010. From publications to public actions: when conservation biologists bridge the gap between research and implementation. BioScience, 60, 835-842.

Bednarek, A. T., Wyborn, C., Cvitanovic, C., et al. 2018. Boundary spanning at the science-policy interface: the practitioners' perspectives. Sustainability Science, 13, 1175-1183. https://doi.org/10.1007 |s11625-018-0550-9

Bennett, N. J., Roth, R., Klain, S. C., et al. 2017b. Conservation social science: understanding and integrating human dimensions to improve conservation. Biological Conservation, 205, 93-108.

Bennett, N. J., Roth, R., Klain, S. C., et al. 2017c. Mainstreaming the social sciences in conservation. Conservation Biology, 31, 56-66.

Bennett, N. J., Teh, L., Ota, P., et al. 2017a. An appeal for a code of conduct for marine conservation. Marine Policy, 81, 411-418. 
Blicharska, M. \& Grandin, U. 2015. Why protect biodiversity? Perspectives of conservation professionals in Poland. International Journal of Biodiversity Science Ecosystem Services \& Management, 11, 349-362.

Bodin, O. 2017. Collaborative environmental governance: achieving collective action in social-ecological systems. Science, 357 (6352).

Brockington, D. 2007. Forests, community conservation, and local government performance: the village forest reserves of Tanzania. Society and Natural Resources, 20, 835-848.

Caplan, N. 1979. The two-communities theory and knowledge utilization. American Behavioral Scientist, 22, 459-470.

Cash, D., Clark, W. C., Alcock, F., et al. 2002. Salience, credibility, legitimacy and boundaries: linking research, assessment and decision making. KSG Working Paper Series RWP02-046. http://dx.doi.org/10 $.2139 /$ ssrn.372280

Chambers, R. 1997. Whose Reality Counts? Putting the First Last. London: ITDG Publishing.

Chapin, F. S. 2017. Now is the time for translational ecology. Frontiers in Ecology and the Environment, 15, 539.

Chilvers, J. \& Kearnes, M. 2016. Remaking Participation. Science, Environment and Emerging Publics. Abingdon: Routledge.

Chilvers, J., Pallett, H. \& Hargreaves, T. 2017. Public engagement with energy: broadening evidence, policy and practice. Briefing note to the UK Energy Research Centre. Available from www.ukerc.ac.uk/ publications/public-engagement-withenergy.html

Colloff, M. J., Lavorel, S., van Kerkhoff, L. E., et al. 2017. Transforming conservation science and practice for a postnormal world. Conservation Biology, 31, 1008-1017.

Colvin, R. M., Witt, G. B. \& Lacey, J. 2016. Approaches to identifying stakeholders in environmental management: insights from practitioners to go beyond the "usual suspects”. Land Use Policy, 52, 266-276.
Cook, C. N., Mascia, M. B., Schwartz, M. W., et al. 2013 Achieving conservation science that bridges the knowledge-action boundary. Conservation Biology, 27, 669-678.

Cowie, A. L., Orr, B. J., Castillo Sanchez, V. M., et al. 2018. Land in balance: the scientific conceptual framework for Land Degradation Neutrality. Environmental Science and Policy, 79, 25-35.

Cvitanovic, C., Hobday, A. J., van Kerkhoff, L., et al. 2015. Improving knowledge exchange among scientists and decision-makers to facilitate the adaptive governance of marine resources: a review of knowledge and research needs. Ocean and Coastal Management, 112, 25-35.

de Vente, J., Reed, M. S., Stringer, L. C., et al. 2016. How does the context and design of participatory decision making processes affect their outcomes? Evidence from sustainable land management in global drylands. Ecology and Society, 21(2), 24.

Elliott, L., Ryan, M. \& Wyborn, C. 2018. Global patterns in conservation capacity development. Biological Conservation, 221, 261-269.

Enquist, C. A. F., Jackson, S. T., Garfin, G. M., et al. 2017. Foundations of translational ecology. Frontiers in Ecology and the Environment, 15, 541-550.

Evans, M. C. 2016. Deforestation in Australia: drivers, trends and policy responses. Pacific Conservation Biology, 22, 130-150.

Evans, M. C., Davilla, F., Toomey, A., et al. 2017. Embrace complexity to improve conservation decision making. Nature Ecology \& Evolution, 1, 1588.

Farwig, N., Ammer, C., Annighöfer, P., et al. 2017. Bridging science and practice in conservation: deficits and challenges from a research perspective. Basic and Applied Ecology, 24, 1-8.

Fraser, E. D. G., Dougill, A. J., Mabee, W. E., et al. 2006. Bottom up and top down: analysis of participatory processes for sustainability indicator identification as a pathway to community empowerment and 
sustainable environmental management. Journal of Environmental Management, 78, 114-127.

Gardner, C. J., Waeber, P. O., Razafindratsima, O. H., et al. 2018. Decision complacency and conservation planning. Conservation Biology, 32, 1469-1472. https://doi.org/10.1111/cobi.13124

Gibbons, P., Zammit, C., Youngentob, K., et al. 2008. Some practical suggestions for improving engagement between researchers and policy-makers in natural resource management. Ecological Management and Restoration, 9, 182-186.

Gibbons, P., Evans, M. C., Maron, M., et al. 2015. A loss-gain calculator for biodiversity offsets and the circumstances in which no net loss is feasible. Conservation Letters, 9 , 252-259.

Global Environment Facility (GEF) Blue Carbon Project. 2017. Blue carbon code of conduct. Available from https://news .gefblueforests.org/blue-carbon-code-ofconduct

Granek, E. E. \& Brown, M. A. 2005. Comanagement approach to marine conservation in Mohéli, Comoros Islands. Conservation Biology, 19, 1724-1732.

Hallett, L. M., Morelli, T. L., Gerber, L. R., et al. 2017. Navigating translation ecology: creating opportunities for scientist participation. Frontiers in Ecology and the Environment, 15, 578-586.

Hauraki Gulf Forum. 2011. State of our gulf: Tikapa Moana - Hauraki Gulf state of the environment report 2011. New Zealand.

Hauraki Gulf Forum. 2014. State of our gulf: Tikapa Moana - Hauraki Gulf state of the environment report 2014. New Zealand.

Head, B. W. 2015. Relationships between policy academics and public servants: learning at a distance? Australian Journal of Public Administration, 74, 5-12.
IUCN. 2016. IUCN Policy on Biodiversity Offsets. Gland: IUCN.

Jackson, S. T., Garfin, G. M. \& Enquist, C. A. F. 2017. Toward an effective practice of translational ecology. Frontiers in Ecology and the Environment, 15, 540.

Jarvis, R. M. 2015. Putting people back in the picture: a social research agenda for a social-ecological approach to conservation. $\mathrm{PhD}$ thesis, Auckland University of Technology.

Jarvis, R. M., Bollard Breen, B., Krägeloh, C. U., et al. 2015b. Citizen science and the power of public participation in marine spatial planning. Marine Policy, 57, 21-26.

Jarvis, R. M., Bollard Breen, B., Krägeloh, C. U., et al. 2016. Identifying diverse conservation values for place-based spatial planning using crowdsourced voluntary geographic information. Society \& Natural Resources, 29, 603-616.

Jarvis, R. M., Borrelle, S. B., Bollard Breen, B., et al. 2015a. Conservation, mismatch and the research implementation gap. Pacific Conservation Biology, 21, 105-107.

Kareiva, P. \& Marvier, M. 2007. Conservation for the people. Scientific American, 297, 50-57.

Keeler, B. L., Chaplin-Kramer, R., Guerry, A. D., et al. 2017. Society is ready for a new kind of science - is academia? BioScience, 67, 591-592.

Kleiber, D. L., Harris, L. M. \& Vincent, A. 2015. Gender and small-scale fisheries: a case for counting women and beyond. Fish and Fisheries, 16, 547-562.

Kothari A., Camill, P. \& Brown, J. 2013. Conservation as if people also mattered: policy and practice of community-based conservation. Conservation and Society, 11, 1-15.

Lacey, J., Howden, M., Cvitanovic, C., et al. 2018. Understanding and managing trust at the 
climate science-policy interface. Nature Climate Change, 8, 22-28.

Lawton, J. H. 2007. Ecology, politics and policy. Journal of Applied Ecology, 44, 465-474.

Lazos-Chavero, E., Zinda,J. Bennett-Curry, A., et al. 2016. Stakeholders and tropical reforestation: challenges, trade-offs, and strategies in dynamic environments. Biotropica, 48, 900-914.

Littell, J. S., Terrando, A. J. \& Morelli, T. L. 2017. Balancing research and service to decision-makers. Frontiers in Ecology and the Environment, 15, 598.

Maron, M., Bull, J. W., Evans, M. C., et al. 2015. Locking in loss: baselines of decline in Australian biodiversity offset policies. Biological Conservation, 192, 504-512.

Maron, M., Ives, C. D., Kujala, H., et al. 2016. Taming a wicked problem: resolving controversies in biodiversity offsetting. BioScience, 66, 489-498.

Marshall, N., Adger, N., Attwood, S., et al. 2017. Empirically derived guidance for social scientists to influence environmental policy. PLOS ONE, 12(3), e0171950.

Maseyk, F., Barea, L., Stephens, R., et al. 2016. A disaggregated biodiversity offset accounting model to improve estimation of ecological equivalency and no net loss. Biological Conservation, 204, 322-332.

Miller, K. L., Trezise, J. A., Kraus, S., et al. 2015. The development of the Australian environmental offsets policy: from theory to practice. Environmental Conservation, 42, 306-314.

Miller, C. A. \& Wyborn, C. 2018. Co-production in global sustainability: histories and theories. Environmental Science \& Policy, https://doi.org/10.1016/j .envsci.2018.01.016

Mukherjee, N., Hugé, J., Sutherland, W. J., et al. 2015. The Deplhi technique in ecology and biological conservation: applications and guidelines. Methods in Ecology and Evolution, 6, 1097-1109.

Mukherjee, N., Zabala, A., Hugé, J., et al. 2018. Comparison of techniques for eliciting views and judgements in decision-making, Methods in Ecology and Evolution, 9, 54-63.

Neßhöver, C., Vandewalle, M., Wittmer, H., et al. 2016. The Network of Knowledge approach - improving the science and society dialogue on biodiversity and ecosystem services in Europe. Biodiversity and Conservation, 25, 1215-1234.

Nel, J. L., Roux, D. J., Driver, A., et al. 2016. Knowledge co-production and boundary work to promote implementation of conservation plans. Conservation Biology, 30, 176-188.

Newell, P., Pattberg, P. \& Schroeder, H. 2012. Multiactor governance and the environment. Annual Review of Environment and Resources, 37, 365-387.

Newman, J., Cherney, A. \& Head, B. W. 2016. Do policy-makers use academic research? Reexamining the "Two Communities" theory of research utilization. Public Administration Review, 76, 24-32.

Nguyen, V. M., Young, N. \& Cooke, S. J. 2017. A roadmap for knowledge exchange and mobilization research in conservation and natural resource management. Conservation Biology, 31, 789-798.

Nyumba, T. O., Wilson, K., Derrick, J., et al. 2018. The use of focus group discussion methodology: insights from two decades of application in conservation. Methods in Ecology and Evolution, 9, 20-32.

Owens, S. 2015. Knowledge, Policy, and Expertise: The UK Royal Commission on Environmental Pollution 1970-2015. Oxford: Oxford University Press.

Reed, M. S., Graves, A., Dandy, N., et al. 2009. Who's in and why? A typology of stakeholder analysis methods for natural 
resource management. Journal of

Environmental Management, 90, 1933-1949.

Reed, M. S., Vella, S., Challies, E., et al. 2017. A theory of participation: what makes stakeholder and public engagement in environmental management work? Restoration Ecology, 26(S1), S7-S17.

Rose, D. C. 2014a. Five ways to enhance the impact of climate science. Nature Climate Change, 4, 522-524.

Rose, D. C. 2014b. Boundary work. Nature Climate Change, 4, 1038.

Rose, D. C. 2018. Avoiding a post-truth world: embracing post-normal conservation science. Conservation and Society, 16, 518-524.

Rose, D. C., Brotherton, P. M., Owens, S., et al. 2018a. Honest advocacy for nature: presenting a persuasive narrative for conservation. Biodiversity and Conservation, 27, 1703-1723.

Rose, D. C., Mukherjee, N., Simmons, B. I., et al. 2017. Policy windows for the environment: tips for improving the uptake of scientific knowledge. Environmental Science and Policy, http://dx.doi.org/10.1016/j .envsci.2017.07.013

Rose, D. C., Sutherland, W. J., Amano, T., et al. 2018b. The major barriers and their solutions for evidence-informed conservation policy. Conservation Letters, 11 (5), e12564. https://doi.org/10.1111/conl .12564

Roux, D. J., Nel, J. L., Cundill, G., et al. 2017. Transdisciplinary research for systemic change: who to learn with, what to learn about and how to learn. Sustainability Science, 12, 711-726.

Sea Change - Tai Timu Tai Pari. 2017. Sea Change - Tai Timu Tai Pari Hauraki Gulf Marine Spatial Plan. Available from www .seachange.org.nz/Read-the-Plan/
Spencer, C., McVay, P. \& Sheridan, S. 2014. Evaluation of the National Environmental Research Program (NERP).

Soulé, M. E. 1985. What is conservation biology?, BioScience, 35, 727-734.

Sterling, E. J., Betley, E., Sigouin, A., et al. 2017. Assessing the evidence for stakeholder engagement in biodiversity conservation. Biological Conservation, 209, 159-171.

Sutherland, W. J., Shackelford, G. \& Rose, D. C. 2017. Collaborating with communities: co-production or co-assessment? Oryx, 51, 569-570.

Sutherland, W. J. \& Wordley, C. F. R. 2017. Evidence complacency hampers conservation. Nature Ecology \& Evolution, 1, 1215-1216.

Toomey, A. H., Knight, A. T. \& Barlow, J. 2016. Navigating the space between research and implementation in conservation: researchimplementation spaces. Conservation Letters, 10, 619-625.

Tyler, C. 2017. Wanted: academics wise to the needs of government. Nature, 552, 7.

Wall, T. U., McNie, E. \& Garfin, G. M. 2017. Use-inspired science: making science usable and useful to decision-makers. Frontiers in Ecology and the Environment, 15, 551-559.

Walsh, J. C., Dicks, L. V. \& Sutherland, W. J. 2015. The effect of scientific evidence on conservation practitioners' management decisions. Conservation Biology, 29, 88-98.

Waylen, K. A., Fischer, A., McGowan, P. J. K., et al. 2010. Effect of local cultural context on the success of community-based conservation interventions. Conservation Biology, 24, 1119-1129.

Wyborn, C. A. 2015. Connecting knowledge with action through coproductive capacities: adaptive governance and connectivity conservation. Ecology and Society, 20, 11. 
Young, J. C., Jordan, A., Searle, K. R., et al. 2013. Does stakeholder involvement really benefit biodiversity conservation? Biological Conservation, 158, 359-370.

Young, J. C., Rose, D. C., Mumby, H. S., et al. 2018. A methodological guide to using and reporting on interviews in conservation science research. Methods in Ecology and Evolution, 9, 10-19.

Young, J. C., Waylen, K. A., Sarkki, S., et al. 2014. Improving the science-policy dialogue to meet the challenges of biodiversity conservation: having conversations rather than talking at one-another. Biodiversity and Conservation, 23, 387-404. 